\title{
Ultra-Highly Diluted Homeopathic Remedies Have Demonstrable Anti-Viral Effects: A Commentary on Our Published Findings Related to Experimental Phage Infectivity in Bacteria
}

\author{
Anisur Rahman Khuda Bukhsh* \\ Department of Zoology, University of Kalyani, India
}

Received: 制: September 05, 2018; Published: 盋 September 11, 2018

*Corresponding author: Anisur Rahman Khuda-Bukhsh, Department of Zoology, University of Kalyani, B-2/325, Kalyani-741235, W.B., India

"Dedicated in memory of Dr. Peter Fisher, a pillar of homeopathy"

\begin{abstract}
We tested if some ultra-highly diluted (by a factor of $10^{60}$ ) homeopathic remedies could induce demonstrable enhanced resistance to the bacteria, Escherichia coli, against infectivity potentials of the host-specific DNA bacteriophage- $\Phi X 174$. Evaluation of anti-viral efficacy, if any, of certain homeopathic remedies with claimed anti-viral effect was made with the aid of the 'bacteriophage assay system' by 'top layer agar plating' method of plaque counting. The number of plaques was recorded in agar-plated petri dishes, containing different drug-treated ( $1 \% \mathrm{v} / \mathrm{v}$; Belladonna 30C, Rhus Tox 30C, Arnica 30C, and subsequently Aconite 30C) or placebo treated (succussed 1\% "alcoholic vehicle" of the drug, Alc-30C, considered placebo or +tive control) bacteria plus the untreated phage mixture. The plaques actually represented the colony of bacteria lysed (or infected) by the phage $\Phi X 174$. Conversely, we exposed $\Phi$ X174 to the homeopathic drugs and placebo before allowing them to interact with the untreated bacteria to ascertain if the drug itself had any direct effect on infective potential of the phage DNA entering into the bacterial cell.

The "blinded" observers noted that each of homeopathic remedy showed significant decrease in plaque numbers in petri dishes with pretreated (1h prior to infection) bacteria as compared to untreated and placebo-treated controls; however, only insignificant change in plaque number was noted when $\Phi X 174$ were pre-treated with the drugs. Thus, the plaque formation directly related to the constitutive expression of E gene (lysis gene) of the phage when inside E. coli, was apparently "blocked" partially by the homeopathic remedies, presumably by inactivation of the E gene by a product of the host genome known to be regulated by a cluster of genes, providing evidence for the ultra-highly diluted homeopathic remedies to have anti-viral effects and ability to modulate expression of certain relevant gene(s) even in bacteria with a simple genetic system
\end{abstract}

Keywords: ФX174 Phage; Escherichia Coli; Homeopathy; Ultra-High Dilution; Gene Expression; Plaque; Molecular Mechanism; Anti-Viral Remedies

\section{Introduction}

The successful use of ultra-highly diluted remedies in homeopathy for more than past two hundred years, particularly those diluted above Avogadro's limit (potency 12C and above, with a dilution factor of $10^{24}$ and above) and their claimed efficacy in removal of diverse disease symptoms in man and veterinary animals have periodically been challenged and become a subject of hot debate among a section of the scientific community, rationalists and the users. This also initiated extensive research in recent years by utilizing various scientific models to test efficacy of the ultra-highly diluted homeopathic remedies and to understand the underlying possible mechanism of action based on proper scientific evidences. Khuda-Bukhsh [1] proposed a working hypothesis in 1997 that the potentized homeopathic remedies could act through regulation of gene expression, and subsequently his group demonstrated the ability of potentized remedies to alter some transcriptomes, possibly through epigenetic modifications [2-5], and further works were initiated particularly in the laboratory of
Khuda-Bukhsh and elsewhere towards accumulating experimental data on homeopathy in various aspects.

To our knowledge, till the end of the first decade of this century, no prominent scientific work had been carried out to ascertain if the ultra-highly diluted homeopathic drugs also had demonstrable effects in the lower organisms like bacteria [6-7] or any unicellular fungi [8] and thus the mechanism(s) of action could also be further scientifically explored and extended in the lower organisms. In this study under commentary, Khuda-Bukhsh and his collaborators [9] used a unique model involving certain bacteria and bacteriophages as experimental materials. The bacteriophages or phages comprise a group of viruses that live and grow in bacterial cells. ФX174 is one such phage that lives specifically in the bacterial host, Escherichia coli. ФX174 characteristically contains a circular single-stranded DNA that replicates through a double-stranded replicative form of DNA [10] in their host, E coli. This phage is a popular model for conducting many landmark experiments because of certain special 
advantages. First, the virion DNA can be completely synthesized with DNA polymerase, using the intact genome as a template [11]. It also happened to be the first DNA that could be completely sequenced [12].

Second, ФX174 accomplishes host lysis (plaque formation) through activation of a single gene $\mathrm{E}$ and its product does not have any other enzymatic activity $[13,14]$, unlike what happens in some other phages such as lambda $(\lambda)$ and T4, which accomplish their infectivity by using more than one gene regulatory circuit/ system (for both lytic and lysogenic cycles) [15]. Therefore, ФX174 phage infectivity in E. coli is considered useful as a good experimental model to study the expression of gene $\mathrm{E}$ and any phenotypic change involving plaque number in the bacterial colony due to $\Phi \times 174$ infection should also be logically attributed to the altered expression of gene $\mathrm{E}$ inside the bacteria, either as a result of "blockage/repression" of the gene E or as a result of nick in the virus DNA affecting E gene expression, and thereby inactivating proper functioning of the viral genome, specifically in regard to inactivation of the constitutive expression potential of the gene E. In bacteriophages, switching off/on of lysogenic or lytic cycle is strictly dependent on nutrients, chemical compounds and also environmental factors like exposure to UV, X-ray etc.) [16].

However, an added advantage with $\Phi \mathrm{X} 174$ as an experimental model is for the absence of any lysogenic gene in this phage; it has only the active lytic gene, the profile of which can also be altered by some external factors $[17,18]$. Further, the phage infection usually does not otherwise interrupt protein, DNA, or RNA synthesis of the host cell [19], including ability to synthesize an inducible enzyme in the host. ФX mRNA made in the infected cell has a base sequence identical to the single stranded DNA contained in the virus [20].

The rationality and use of ultra-highly diluted remedies above 12C that is not expected to contain any original drug molecules in homeopathy is considered by many to be an enigmatic scientific issue, particularly when the mechanism of action is not clearly known. Thus, in this study, the homeopathic remedies were consciously selected to be the $30 \mathrm{C}$, or with a dilution factor of $10^{60}$ to examine if such a high dilution could have any demonstrable effect in the lower organism, not studied earlier.

In this paper the experiment was designed in such a way to be able to address the following research questions like: i) if ultra-highly diluted homeopathic remedies (beyond Avogadro's limit) could elicit responses (protective) in the lower animals like bacteria with a simple genetic system (prokaryote), ii) if certain homeopathic drugs used against common viral diseases could also elicit similar responses in the bacteria, Escherichia coli, suggestive of their anti-viral effect and iii) if they did, whether it was possible to elucidate the plausible mechanism at the molecular level, in respect of expression of certain genes.

\section{Materials and Methods}

The bacteriophage $\Phi \times 174$ wild type and its host bacterial strain E. coli C/1 (a spontaneous phage T1 resistant mutant) were maintained in the standard Luria Bertani (LB) medium and starvation buffer (SB) preparations were used [9]. All standard conditions for maintaining the culture and experimental set-ups were properly followed (for details consult ref [9]). Briefly, the stock of phage was prepared $[21,22]$ with slight modification: bacteria (E. coli $\mathrm{C} / 1$ ) were grown in $\mathrm{LB}$ with aeration and the culture was infected with phage when it was in the logarithmic (log) phase of growth (about 108 cells $/ \mathrm{ml}$ ). For ensuring that all of the cells in the population were at a similar stage of development, the experiments were done with starved synchronized cells, made in the following way [9] with little modification.; the cells were allowed to starve with shaking at $37^{\circ} \mathrm{C}$ for $1 \mathrm{~h}$ for synchronization and methods of plaque assay [22] by count of numbers of infective centres or the plaque forming units (PFU) of the bacteriophage following the double layer agar plating method [9] were adopted.

The potentized homeopathic drugs used in this study, namely, Rhus toxicodendron (Rhus Tox 30C) and Atropa belladonna (Belladonna 30C) are clinically used with great success to remove symptoms of common viral diseases like influenza with cough and cold [23]; However, the other remedy, Arnica montana (Arnica 30C;) is claimed to have mainly effects against shock, trauma and injury, but not particularly claimed to have any antiviral effect. These homeopathic remedies prepared as per standard Indian Homeopathic Pharmacopaea, were procured from HAPCO, BB Ganguly Street, Kolkata. The drugs prepared in ethanolic media (and the placebo or positive control prepared from the same stock as the drug and succussed appropriately to make it succussed alcohol 30C) were suitably diluted to bring it down to $1 \%$ ethanolic strength to minimize alcoholic effect on the microbes. The data presented were statistically analyzed from two sub-sets of experiments and three replicates of each sub-set. Briefly, the mixtures containing specific numbers of $E$. coli and the bacteriophages that produced a fairly constant number of plaques were first standardized.

The starved synchronized cells were then allowed to grow in fresh LB in presence of ( $1 \% \mathrm{v} / \mathrm{v})$ of different homeopathic remedies or the Alc 30C, separately.; b) the cells were further shifted to SB by centrifugation; c) normal phage was added to such cells at multiplicity of infection ratio of 1.0; d) the phage adsorbed cells were then serially diluted in SB; e) subsequent steps to obtain PFU were done as described in the original paper [9].. The observers were "blinded" during observation. In another subset, the phage was allowed to incubate in presence of $(1 \% \mathrm{v} / \mathrm{v})$ of different homeopathic remedies or Alc 30C in the similar way.

\section{Result}

In the drug untreated control, the mean number of plaques observed was $115.4 \pm 1.6$ ) as against $102.2 \pm 2.22$ ) in the placebo treated bacteria. On the other hand, in the Rhus Tox 30C treated bacteria, the number of plaques observed was $12.0 \pm 0.84$ as against 23.60 \pm 2.73 and 54.40 \pm 2.97 in Belladonna 30C and Arnica 30C treated bacteria, respectively. Thus, there was a clear difference noted between the homeopathic remedies claimed to have antiviral effects and the one which is generally used against shock and injury and not claimed as an anti-viral drug, per se. Rhus Tox 30C appeared to have a greater efficacy than Belladonna 30C in rendering protection to the bacteria against the phage attack. In the set of experiments where the phage alone was treated with the 
homeopathic remedies, the number of plaques was $115.20 \pm 4.33$ in the untreated control as against $106.00 \pm 5.33$ in the placebo control. The number of plaques observed in the Rhus Tox 30C treated series was $87.60 \pm 6.33$ as against $96.80 \pm 7.33$ and $86.80 \pm 8.33$ in the Belladonna 30C and Arnica 30C, respectively.

Thus, there was strikingly more number of plaques in the sets where the phage was treated with the drugs whereas the bacteria were not treated, as compared to the sets in which the bacteria were treated with the drugs and the phage were not treated. In subsequently-conducted experiment (data unpublished) with an additional anti-viral drug, Aconite 30C, the plaque count was very low in Aconite like Rhus Tox 30C and Belladonna 30C treatment, while expression of E gene in the Rhus Tox 30C, Belladonna 30C and Aconite 30C treated bacteria was also found to be correspondingly down regulated (Figure 1) as compared to the negative and positive controls. Interestingly, E gene expression in the Arnica 30C treated ones was also quite expectedly not so much down regulated, in conformity with its use as a remedy against shock and injury, not as an anti-viral drug.

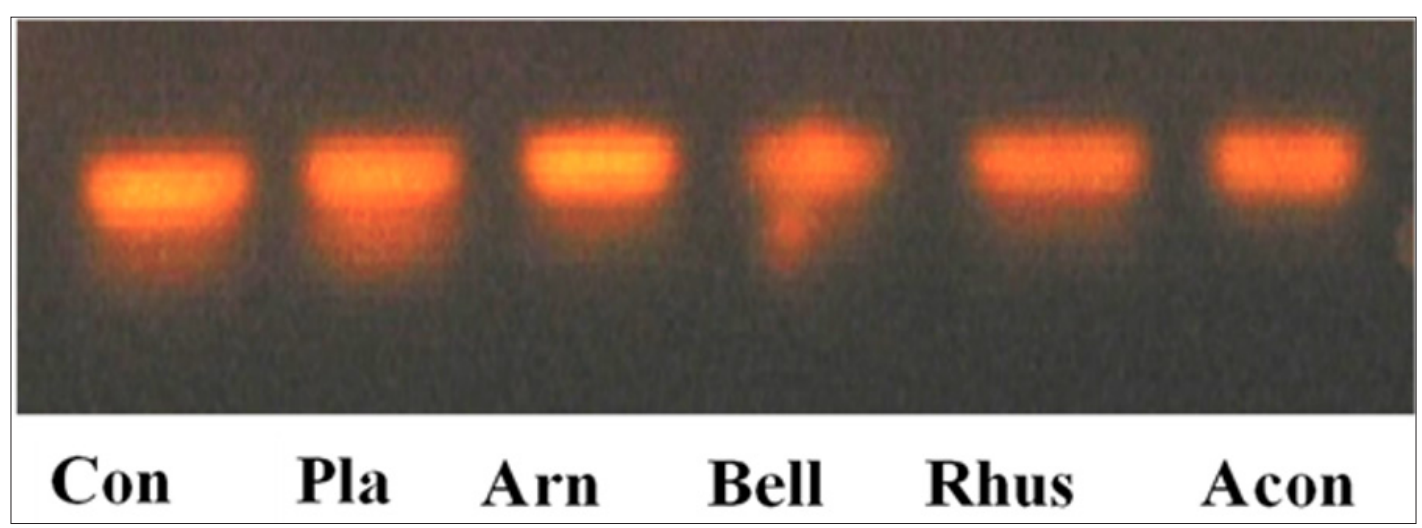

Figure 1: RT-PCR analysis of phage lysis gene E in drug-pretreated and control bacteria E. coli.

\section{Discussion}

The results of the phage infectivity study indicated that both Rhus Tox 30C and Belladonna 30C exposure to E. coli produced much smaller number of plaques than when the bacteria were not exposed to these ultra-highly diluted homeopathic remedies. This ability was not, however, shown as much by Arnica 30C, which is only clinically used in treatment of shock and injury but not in case of any viral disease. On the other hand, the placebo treated bacteria failed to show any such protective effect against the viral infection, as demonstrated by the plaque counts, confirming thereby that it was not just the alcohol effect. However, when the phage was pretreated with these remedies individually, the virus hardly showed any modulation in their ability to attack the bacteria and formed nearly similar number of plaques by their lytic effect comparable to when they were drug untreated. Thus, the homeopathic drugs which showed their anti-viral effects when treated to the bacteria did not show their direct anti-viral effect on the phage by way of blocking or reducing their ability to infect the bacteria. So, the homeopathic remedy by itself did not apparently show its ability to directly repress/or inactivate the E gene of the phage, or their constitutive expression inside the bacteria.

On the other hand, when the bacteria were exposed to the drug, they somehow were induced to produce the protein product (restriction enzymes?) that presumably helped them to repress or inactivate the phage $\mathrm{E}$ gene expression inside the bacteria. Thus, the plaque numbers were phenotypically reduced. This would provide strong circumstantial evidence that some inherent genes of the bacteria, which are already endowed with the property to produce such repressor proteins to protect themselves from phage attack, might have been accelerated further to produce additional amount of the "repressor" molecules to block the E gene expression of the phage. When we subsequently measured E gene expression in phages of different groups of the drug treated and the controls microbes, we found that the expression of E gene was indeed much less in the Rhus Tox, Belladonna and Aconite treated bacteria. Since the phage DNA only entered into the bacterial cell leaving aside the protein coat at the bacterial outer membrane, it was only possible for the bacteria to stop the phage attack by blocking the expression of the lytic gene $\mathrm{E}$ which otherwise is programmed to constitutively produce the $\mathrm{E}$ gene product when inside the bacteria that is responsible for the lysis of bacteria.

Alternatively, the phage DNA could have been randomly fragmented as and when they entered, by some unknown gene products of the bacteria. In fact, many microbes rely on diverse defence mechanisms that allow them to withstand viral predation and exposure to invading nucleic acid. In many bacteria, clustered regularly interspaced short palindromic repeats (CRISPR) are reported to form peculiar genetic loci, which provide acquired immunity against viruses and plasmids by targeting nucleic acid in a sequence-specific manner [24,25]. These hyper-variable loci take up genetic material from invasive elements and build up inheritable DNA-encoded immunity over time. The homeopathic remedies apparently could have enhanced the activity of these genetic clustered elements, so that the bacteria could be endowed with the ability to deactivate the constitutively expressing phage $\mathrm{E}$ gene as they entered.

We reported in our earlier studies [6-8] by utilizing reversetranscriptase polymerase chain reaction (RT-PCR) methods that introduction of homeopathic drugs is capable of bringing about changes in the gene expression of the bacterial system, both at the m-RNA and DNA levels, when exposed to other toxic insults. Khuda-Bukhsh and his group have long been advocating [1,26-33] 
that the potentized homeopathic drugs could possibly act through regulation of gene expression, with exhaustive experimental evidences from both the higher organisms like mammals and lower organisms like yeast and bacteria. The results of the study under commentary provide yet another strong evidence of the capability of the potentized homeopathic drugs to trigger specific gene activity in the bacteria to render protective effects against phage attack. Since there is hardly any anti-viral drug without toxicity in the modern drug regimen, the results of the study assume special significance. The present findings would give support for the use of these potentized drugs more assuredly against influenza and other viral diseases.

\section{References}

1. Khuda Bukhsh AR (1997) Potentized homeopathic drug act through regulation of gene expression: a hypothesis to explain their mechanism and pathways of action in vivo. Comp Ther Med 5: 43-46.

2. Bishayee K, Sikdar S and Khuda Bukhsh AR (2013) Evidence of an Epigenetic Modification in Cell-cycle Arrest Caused by the Use of Ultrahighly-diluted Gonolobus Condurango Journal of Pharmacopuncture 16: 7-13.

3. Saha SK, Khuda Bukhsh AR (2014) Berberine alters epigenetic modifications, disrupts microtubule network, and modulates HPV-18 E6-E7 oncoproteins by targeting p53 in cervical cancer cell HeLa: a mechanistic study including molecular docking. Eur J Pharmacol 744: 132-146.

4. Khuda Bukhsh AR, Sikdar S (2015) Condurango 30C induces epigenetic modification of lung cancer-specific tumour suppressor genes via demethylation. Forsch Komplementmed 22: 172-179.

5. Saha SK, Roy S, Khuda Bukhsh AR (2015) Ultra-highly diluted plant extracts of Hydrastis canadensis and Marsdenia condurango induce epigenetic modifications and alter gene expression profiles in HeLa cells in vitro. J Intgr Med 13: 400-411.

6. Khuda Bukhsh AR, De A, Das D, Dutta S, Boujedaini N (2011) Analysis of the capability of ultra-highly diluted glucose to increase glucose uptake in arsenite stressed bacteria Escherichia coli. J Chin Integr Med/ Zhong Xi Yi Jie He Xue Bao 9: 901-912.

7. De A, Das D, Dutta S, Chakraborty D, Boujedaini N, et al. (2011) Potentized homeopathic drug, Arsenicum Album 30C, inhibits intracellular ROS generation and up-regulates expression of arsenic resistance gene in arsenic exposed bacteria, Escherichia coli. Zhong Xi Yi Jie He Xue Bao,10: 210-227.

8. Das D, Dutta S, Biswas R, Boujedaini N, Khuda Bukhsh AR, et al. (2011) Potentized homeopathic drug Arsenicum Album 30C positively modulates protein biomarkers and gene expressions in Saccharomyces cerevisae exposed to arsenate. J Chin Integr Med / Zhong Xi Yi Jie He Xue Bao 9: 752-560.

9. Saha SK, Das Sreemanti, Khuda Bukhsh AR (2012) Phenotypic evidence of ultrahighly diluted homeopathif remedies acting at gene expression level: a novel probe on experimental phage inectivity.Journal of Chinese Integrative Medicine 10: 462-470.

10. Arai K, Low R, Kobori J, Shlomai J (1981) Mechanism of dnaB protein action. V. Association of dnaB protein, protein n', and other repriming proteins in the primosome of DNA replication. J Biol Chem 256: 5273-80.

11. Goulian M, Kornberg A, Sinsheimer RL (1967) Enzymatic synthesis of DNA, XXIV. Synthesis of infectious phage $\Phi$-X174 DNA. Proc Natl Acad Sci 58: 2321-2328.

12. Sanger F, Coulson AR, Friedmann T, Air GM, Barrell BG, et al. (1978) The nucleotide sequence of bacteriophage $\Phi X X 174$. J Mol Biol 125: 225-246.
13. Witte A, Lubitz W (1989) Biochemical characterization of $\Phi X 174-$ protein-E-mediated lysis of Escherichia coli. Eur J Biochem 180: 393398.

14. Markert A, Zillig W (1965) Studies on the lysis of Escherichia coli C by bacteriophage $\Phi X 174$. Virology 25: 88-97.

15. Cao Y, Lu HM, Liang J (2008) Stochastic probability landscape model for switching efficiency, robustness, and differential threshold for induction of genetic circuit in phage $\lambda$. IEEE EMBS 1: 611-614.

16. Khan NC, Poddar RK (1974) Photodynamic inactivation of antigenic determinants of single stranded DNA bacteriophage $\Phi X 174$. J Virol 13: 997-1000.

17. Mik G De, Groot I De (1977) Mechanisms of inactivation of bacteriophage ФX174 and its DNA in aerosols by ozone and ozonized cyclohexene. J Hyg (Lond) 78: 199-211.

18. Hsu WT, Lin EJ, Harvey RG, Weiss SB (1977) Mechanism of phage $\Phi X 174$ DNA inactivation by benzo(a)pyrene-7,8-dihydrodiol-9,10-epoxide. Proc Natl Acad Sci 74: 3335-339.

19. Rueckert RR, Zillig W (1962) Biosynthesis of virus protein in Escherichia coli $C$ in vivo following infection with bacteriophage $\Phi X-174$. J Mol Biol 5: $1-9$.

20. Hayasi M, Hayasi MN, Spiegelman (1963) Restriction of in vivo genetic transcription to one of the complementary strands of DNA. Proc Natl Acad Sci 50, pp. 664.

21. Dulbecco R (1950) Experiments on photoreactivation of bacteriophages inactivated with ultraviolet radiation. J Bacteriol 59: 329-347.

22. Denhardt DT, Sinsheimer RL (1965) The process of infection with bacteriophage $\Phi X 174$. Phage maturation and lysis after synchronized infection. J Mol Biol 12: 641-646.

23. Saha S, Jana B, Basu T (2007) The two inducible responses, SOS and heatshock, in Escherichia coli act synergistically during Weigle reactivation of the bacteriophage $\Phi X 174$. Int J Radiat Biol 83: 463-469.

24. Hovarth, Berrangou (2010) CRISPR/cas, the immune system of bacteria and Archaea. Science 327: 167-170.

25. Makarova KS, Wolf YI, Snir S, Koonin EV (2011) Defence islands in bacterial and archeael genomes and prediction of novel defence systems. Journal of Bacteriol 193: 6039-6056.

26. Khuda Bukhsh, AR (2003) Towards understanding molecular mechanisms of action of homeopathic drugs: an overview. Mol Cell Biochem 253: 339-345.

27. Mallick P, Chakrabarti Mallick J, Guha B, Khuda Bukhsh AR (2003) Ameliorating effect of micro doses of a potentized homeopathic drug Arsenicum album, on arsenic induced toxicity in mice. BMC Complement Altern Med 3: 1-18.

28. Khuda Bukhsh AR (2006) Laboratory research in homeopathy: pro. Integr Cancer Ther 5: 320-332.

29. Khuda Bukhsh AR, Pathak S (2008) Homeopathic drug discovery: theory update and methodological aspect. Expert Opin Drug Discov 3: 979-990.

30. Khuda Bukhsh AR (2009) Mice as a model for homeopathy research. Homeopathy 98: 267-279.

31. Khuda Bukhsh AR (2014) Current trends in ultra-high dilution research with particular reference to gene regulatory hypothesis: Review article. The Nucleus (Springer) Nucleus 57: 3-17.

32. Khuda Bukhsh AR (2017) An overview of research at University of Kalyani in exploring some basic issues of Homoeopathy. Indian Journal of Research in Homeopathy 11: 147-157.

33. Khuda Bukhsh AR, Bhattacharyya SS, Paul S, Dutta S, Boujedaini N, et al. (2009) Modulation of Signal Proteins: A Plausible Mechanism to Explain How a Potentized Drug Secale Cor 30C Diluted beyond Avogadro's Limit Combats Skin Papilloma in Mice. 
ISSN: 2574-1241

DOI: 10.26717/BJSTR.2018.08.001727

Anisur Rahman Khuda Bukhsh. Biomed J Sci \& Tech Res

(C) (i) This work is licensed under Creative

Submission Link: https://biomedres.us/submit-manuscript.php

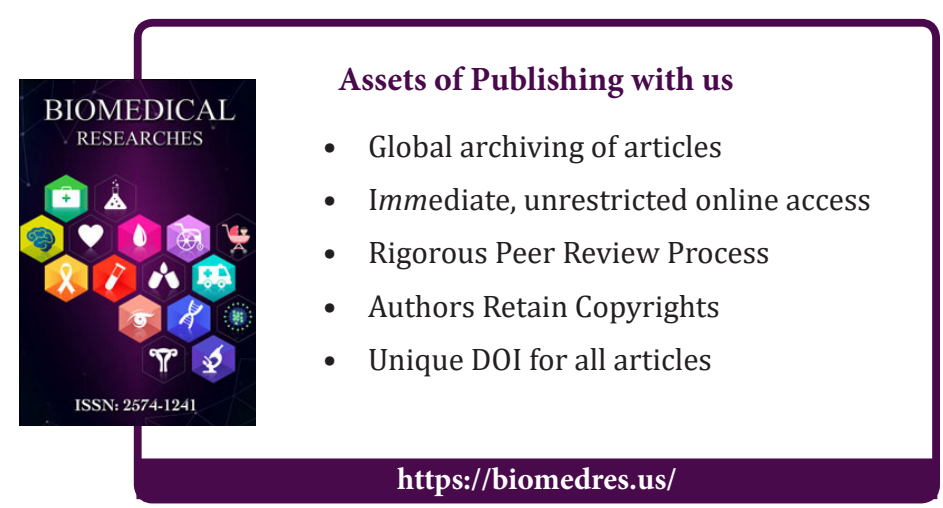

